\title{
Simulating the Evolution of Business Models for Electricity Recharging Infrastructure Development by 2030: A Case Study for Greece
}

\author{
Stergios Statharas ${ }^{1,2}$, Yannis Moysoglou ${ }^{2}$, Pelopidas Siskos ${ }^{1,2, *}$ and Pantelis Capros ${ }^{1}$ \\ 1 School of Electrical and Computer Engineering, E3MLab, National Technical University of Athens, \\ 9 Iroon Polytechniou Street, Zografou, 15773 Athens, Greece; statharas@e3modelling.com (S.S.); \\ kapros@central.ntua.gr (P.C.) \\ 2 E3-Modelling SA, Panormou 70-72, 11524 Athens, Greece; moysoglou@e3modelling.com \\ * Correspondence: psiskos@e3modelling.com; Tel.: +30-2106775696
}

Citation: Statharas, S.; Moysoglou, Y.; Siskos, P.; Capros, P. Simulating the Evolution of Business Models for Electricity Recharging Infrastructure Development by 2030: A Case Study for Greece. Energies 2021, 14, 2345. https://doi.org/10.3390/ en14092345

Academic Editor: Hongwen He

Received: 13 March 2021

Accepted: 19 April 2021

Published: 21 April 2021

Publisher's Note: MDPI stays neutral with regard to jurisdictional claims in published maps and institutional affiliations.

Copyright: (c) 2021 by the authors. Licensee MDPI, Basel, Switzerland. This article is an open access article distributed under the terms and conditions of the Creative Commons Attribution (CC BY) license (https:/ / creativecommons.org/licenses/by/ $4.0 /)$.

\begin{abstract}
It is widely accepted that the market uptake of electric vehicles is essential for the decarbonisation of transport. However, scaling up the roll out of electric vehicles (EV) is challenging considering the lack of charging infrastructure. The latter is, currently, developing in an uneven way across the EU countries. A charging infrastructure with wide coverage addresses range limitations but requires high investment with uncertain returns during the early years of deployment. The aim of this paper is to assess how different policy options affect EV penetration and the involvement of private sector in infrastructure deployment. We propose a mathematical programming model of the decision problem and the interaction between the actors of EV charging ecosystem and apply it to the case of Greece from the time period until 2030. Greece represents a typical example of a country with ambitious targets for EV penetration by 2030 (10\% of the total stock) with limited effort made until now. The results indicate that it is challenging to engage private investors in the early years, even using subsidies; thus, publicly financed infrastructure deployment is important for the first years. In the mid-term, subsidization on the costs of charging points is necessary to positively influence the uptake of private investments. These are mainly attracted from 2025 onwards, after a critical mass of EVs and infrastructure has been deployed.
\end{abstract}

Keywords: electric vehicles; electricity recharging infrastructure; business models; equilibrium programming; Greek EV mobility 2030; private investments in infrastructure

\section{Introduction}

The mitigation of the GHG emissions from transport constitutes a strategic objective within the energy system decarbonisation strategy. Electrification of private transport is considered as one of the most promising options for transport decarbonisation. This is supported by several long-term scenarios which foresee a massive uptake of electric vehicles (EV), at least in the period after 2030, as a cost-effective option for decarbonisation in the EU [1-5]. The low-carbon transition scenarios envisage electrification of private transport modes associated with substantial reductions in battery costs driven by economies of scale and development of a large network for recharging EVs.

Even though the private transport electrification strategy for the long-term seems clear enough, the existing market barriers, such as the high battery costs and lack of charging infrastructure [6-9], still need to be alleviated. There is a growing consensus that battery costs will continue to decrease over the next decade, continuing the trend that has been observed over the last 5 years [10]. However, even though EVs are close to reaching cost parity on a lifetime costing basis, deployment is still slow due to a number of barriers, including psychological factors, affecting consumers' decisions [11]. Implementing complementary policies focused on the demand side, such as subsidies [12], access to bus 
lanes, parking privileges [13], or on the supply side, such as zero emission vehicle quotas on the total annual sales imposed on car manufacturers $[14,15]$ can alleviate these barriers of EVs by 2030.

However, why do we consider the charging infrastructure as a critical market barrier for a wider EV uptake in the EU? The answer is that electricity recharging points have developed in an uneven way among the EU countries. Currently, the number of charging points developed in France, Netherlands, and Germany represent the vast majority (more than $65 \%$ ) of the total number of charging points in the EU. This would mean that an EV user would have issues aiming to travel outside the three abovementioned countries. While home charging may prove sufficient for the majority of small EVs during the first stages of EV deployment, the development of a robust charging network which enables the supply of fast charging services at key traffic nodes is necessary to achieve high EV penetration $[16,17]$. Several studies confirm a positive correlation between the existence of a public charging infrastructure system and EV adoption rates, although there is uncertainty regarding the direction of causality $[7,18,19]$. Nevertheless, there is evidence that infrastructure is crucial to support the electrification of a greater share of vehicle miles travelled [20]; new BEV purchasers show high willingness to pay (WTP) for paying the use of recharging through public infrastructure [21], yet, there are diminishing returns of such charging infrastructure placement [22]. Moreover, publicly accessible recharging infrastructure is critical if EVs are to be adopted by population segments that do not have off-street parking option $[23,24]$. As the decade 2021-2030 will set the ground for the massive transition towards transport electrification [25], investments in charging infrastructure have to start as soon as possible.

This "chicken-egg" problem [26,27], which characterises the problematic interdependence between EV penetration and infrastructure development, needs to be solved. The development of viable business models for charging infrastructure is critical in order to turn charging infrastructure deployment into an appealing activity for private investors while ensuring an affordable charging price, as well as an adequate network of charging points for EV users. With the term business model, we refer to the ways businesses generate cash flow by offering a product or service (brief overview of the main related business models and their advantages and disadvantages is presented in Section 2.2). The prevailing choice for the success of EVs may not be limited to a single model but can be the result of the simultaneous presence of public and private investments assumed by different models, effectively adapting to the evolving charging needs and aspirations of market actors.

The novelty of the present work is twofold: (i) first, we provide a modelling framework that simulates the interactions and the decision making of the actors involved in EV charging; (ii) then, apply the model to the specific case of the Greece and assess different pathways of EV fleet and charging deployment by 2030. We propose a mathematical program based on a game-theoretic analysis of the actions of the actors of the electromobility system. Through the interactions of the decision makers, the modelling simulates the evolution of the business model for the development of the recharging infrastructure. We carry out scenario analysis to assess the development of the different business models and the uptake of private investments under alternative assumed trajectories on the future costs of EVs and charging points. The quantitative analysis also assesses the impacts of the subsidization of private investors for developing infrastructure to trigger a transition from public to private business model and accelerate the uptake of EVs. The analysis applies specifically to the case of Greece and focuses on the time period between 2021 and 2030. Greece represents a typical example of a country with ambitious targets for EV penetration by 2030, while at the same time limited or no effort has been made up to now. We take on board the Greek national objective to reach an EV penetration of approximately $10 \%$ of the total fleet of cars in 2030, as part of the Greek 2030 national energy and climate targets. This is an ambitious target, considering that the total number of charging points in Greece was about 300 (EAFO statistics) and significantly lower compared to many other EU countries.

The approach proposed aims to advance empirical modelling on this field. Previous research has compared and assessed the viability of selected business models assuming a 
specific business model each time. However, evaluating the impacts of the business models in a static manner does not allow grasping dynamic effects related with the evolution of $\mathrm{EV}$ costs and charging infrastructure. In addition, static approaches do not allow a proper simulation of potential impacts from the demand side (i.e., consumers purchasing EVs). Hence, the developments related to the emergence and the dynamic evolution of electricity charging business models until 2030 as a result of the interactions between the system's agents are yet to be explored. In Section 2.1 we present the literature review on this topic.

The present paper is structured as follows: Section 2 provides a literature review and presents, briefly, the main characteristics of infrastructure business models; Section 3 describes the modelling methodology developed to answer the research questions posed; Section 4 presents the results on different scenarios applied to the case of Greece; Section 5 concludes the paper.

\section{Background}

\subsection{Literature Review and Motivation for Research}

The lack of public charging infrastructure is identified in the literature as a major barrier in the development of the EV market. The analysis in [7] shows that the charging infrastructure coverage can guarantee high EV adoption rates and suggests that the installation of charging stations may be more effective than financial measures. In [6], the review of the factors which influence the economics of public infrastructure, concludes that psychological factors, such as range anxiety, are not yet well understood. Nevertheless, the existence of public charging infrastructure is considered as a key factor for mitigating the range anxiety of EV drivers and encouraging EV usage. Ref. [19] examines the relation between daily driving distance and the power of charging service offered, based on data of EVs and infrastructure usage in the UK and the US. The authors claim that fast chargers enable the usage of EVs for trips of distance above their single-charge range and suggest that the existence of fast charging infrastructure can help overcome range limitations of EVs.

Yet, the actual charging behaviour of EV users needs to be better understood in order to assess the financial viability (from the perspective of the private investor revenues) of public charging stations. Several scientific papers analyse data on charging behaviour to estimate the actual utilization of different charging types. Ref. [16] analyses the charging patterns of electric vehicles using data from the Western Australian Electric Vehicle Trial and the EV Charging Research Network in Perth. Their analysis confirms that most of the EV charging takes place at business location and at home. The authors conclude that slow and semi-fast public charging stations will not be properly utilized when the number of EVs is low and that a fast-DC charging network should be favoured as it will satisfy the segment of charging demand associated with the need for quick full recharge.

In a similar spirit, [17] analyses the consumers' charging behaviour using data on infrastructure usage in Ireland. For fast charging stations in particular, the authors suggest that car park locations recorded the highest usage frequencies, which, in turn, indicates that public fast charging infrastructure can be financially viable in the short- to mid-term. The authors, also, claim that the development of a highly connected network of strategically placed fast charging stations should receive priority. Less favourable findings regarding the utilization of fast public infrastructure are presented in [28]. Choosing Austria as a case study, the authors estimate that less than $2 \%$ of charging events involve the utilization of public charging infrastructure implying profitability issues at the present state. The authors further suggest that fast charging located at highways is likely to be profitable since the willingness-to-pay (WTP) for a fast recharge is expected to be significant. Similar are the findings from a case study based on California's charging network [21], especially related with fast chargers used in both intercity routes and intraregional travels.

A few studies have proposed methodologies to assess the viability of public charging infrastructure assuming different underlying business models. Ref. [29] explores the economic feasibility of different charging infrastructure possibilities, in terms of charging power, ownership of the charging station, and accessibility. The authors conclude that 
home charging is preferred by users who have this capability while the success of a business model for fast charging depends heavily on the utilization of the infrastructure. In [30], authors study the pricing for using charging infrastructure in the context of public-private partnerships and propose a charging pricing model based on a system dynamics technique. Their results indicate that the charging price is heavily influenced by the operating cost, electricity price, and charging volume. In a subsequent work [31], they propose a game theoretic modelling to decide the EV public charging pricing, considering the interests of government, consumers and charging facility operators. The model is applied in different regions of China and the results suggest that governmental subsidies to charging station operators positively affect the uptake of EVs.

While previous works have explored the conditions of viability of selected cases of business models assuming a fixed business model each time, the emergence and evolution of electricity recharging business models, over time, as a result of the interactions between the system's agents have yet to be explored.

\subsection{Defining Business Models for EV Recharging Infrastructure}

A business model can generally be defined as the way in which the members of an economic community generate and share value. According to [32], a business model defines the relationships between different actors (i.e., the direction and the type of the value offered and the flow of payments among the actors). Scaling this abstract definition down to the level of EV charging businesses, the value is associated with extending the effective range of EVs and mitigating range anxiety.

A successful charging infrastructure system generates value indirectly for car manufacturers, parking operators, and retailers via increased EV sales, the attraction of customers who own EVs and the increased customer dwelling time in the business premises. In addition, value is generated indirectly for society overall regardless of their participation in electro-mobility; this value is associated with indirect positive externalities stemming from the reduction in GHG and pollutants emissions. The success of an infrastructure business model depends also on its ability to capture this indirect value.

In the case of the charging infrastructure ecosystem, cash flow is generated from EV consumers who pay the charging providers for their services. The charging providers, in return, pay the electric utilities for the electricity. Alternative schemes foresee the possibility for recovering the capital costs of the charging infrastructure from the electricity bills of all consumers and not only the ones using the infrastructure. Private investors then see the recovery of capital costs as less risky compared to a case where only the EV users pay for the service.

Different business models for EV charging emerge when market actors are assigned different roles. The literature has identified a set of roles that are common among different EV charging business models $[29,33]$. These roles include:

- the electro-mobility service provider (EMSP), who offers electro-mobility services to the end users. The offered services may include, apart from vehicle charging, navigating services;

- the charging station operator (CSO), who is involved in the management, monitoring, and maintenance of a charging station and offers charging to the EMSP based on a business-to-business (B2B) relationship (directly or through a third party);

- the Distribution System Operator (DSO), the owner and operator of the distribution network. The DSO is the entity that maintains and operates the distribution network and provides a platform that allows the connection between the charging station and the electrical utilities.

In accordance with the above, the case of home charging, for example, can be seen as a trivial model in which the EV user acts as EMSP and CSO by satisfying their charging needs using a low power $(3.3 \mathrm{KW})$ home charger. In the case of infrastructure deployment as a competitive market, the market actors (e.g., private investor or private operator) develop, own, and operate publicly accessible high-power (typically around $50 \mathrm{KW}$ ) 
charging stations. This private model meets the evolving needs of EV charging and enjoys the benefits of a competitive market, i.e., optimal cost solutions and high utilization of infrastructure [34]. However, there is the risk of developing charging infrastructure in areas where investors face the lowest investment risks. In addition, the participation of the private sector is subject to the "chicken-egg" dilemma. The UK and Germany are two examples of applications of such a free market approach. In the UK, public-private partnerships, and revenue-sharing arrangements for the rollout of charging infrastructure are gaining increasing popularity in the last few years [35]. In Germany, major utilities in cooperation with car manufacturers are planning the development of charging infrastructure [36], effectively implementing a private market model which captures the value generated for car manufacturers and utilities via increased sales of EVs and increased consumption of electric energy, respectively. Other approaches propose optimising the energy demand of EVs by maximizing owners' profits $[37,38]$ or focusing on the EV charging profiles.

Contrastingly, a prominent example of a public model that assumes a central planning approach for the development of the charging infrastructure is the so-called DSO model; the DSO ensures the deployment of public infrastructure and the roles of EMSP and CSO may either be taken by the DSO or by private actors. Such a model ensures the uniform development of the infrastructure even in regions with lower utilization rates. However, DSO models are not easy to adapt to changing charging needs as infrastructure may be developed based on grid adequacy and may not respond sufficiently to the penetration of EVs; thus, these models are more appropriate for the short-term [39,40]. Typical examples can be found in literature. For instance, in Italy, a DSO model was initially deployed but was later replaced by a free-market model when the regulatory authority perceived investing interest from market actors [39]. In Austria, Ireland, and Luxembourg, a DSO model is adopted where the DSOs own and operate the infrastructure as an extension of their regulated roles-however, the commercial operation of charging stations can be assigned to an external party [41].

Hybrid models may emerge from combining elements of private and public approaches. For example, the charging network may be centrally planned, and the development and operation of charging infrastructure may be assigned to private agents via public tenders. Norway presents an example of such a model; the location of the charging stations is planned along the road network and the charging infrastructure is owned and operated by charging operators who compete for public funding [42]. This model combines the advantage of even infrastructure deployment that is common to central planning approaches with the advantages of decreased costs and higher infrastructure utilization. Nonetheless, this hybrid approach may introduce delays due to the tendering procedures and the danger of binding deployment of charging stations regardless of changes to the EV ecosystem. Table 1 summarizes the characteristics of the different business model approaches.

To resolve the "chicken-egg" problem of the development of the charging infrastructure and the promotion of EVs, the EC put forward a proposal (COM (2016) 864) which aims to harness the advantages of the two approaches. In this respect, Member States may allow the DSOs to be engaged in the development and operation of the recharging infrastructure in case no private investors have expressed interest to invest. After all, government and industry need innovative business models to attract investments [43]. This kind of policy making: (i) supports the development of recharging infrastructure at the early years (if no private investors are interested to be engaged in this business), in order to avoid delaying the uptake of electric vehicles; and (ii) allows the transition towards free market conditions when conditions are mature and a critical mass of charging points and EVs are in place. 
Table 1. Characteristics of private, public, and hybrid business models for infrastructure.

\begin{tabular}{ccccc}
\hline $\begin{array}{c}\text { Business Model } \\
\text { Category }\end{array}$ & $\begin{array}{c}\text { Infrastructure } \\
\text { Deployment }\end{array}$ & Advantages & Disadvantages & Application Examples \\
\hline $\begin{array}{c}\text { Private free market } \\
\text { model }\end{array}$ & Private & $\begin{array}{c}\text { Competition ensures optimal } \\
\text { cost and utilization of } \\
\text { infrastructure }\end{array}$ & $\begin{array}{c}\text { Uneven spatial } \\
\text { deployment, } \\
\text { chicken-egg dilemma }\end{array}$ & Germany, UK, Italy \\
$\begin{array}{c}\text { Public DSO-type } \\
\text { model }\end{array}$ & Public & $\begin{array}{c}\text { Deployment of infrastructure } \\
\text { even in remote areas, } \\
\text { resolution of chicken egg } \\
\text { dilemma }\end{array}$ & $\begin{array}{c}\text { Problematic adaptation } \\
\text { to changing charging } \\
\text { needs }\end{array}$ & $\begin{array}{c}\text { Austria, Ireland, Italy, } \\
\text { Luxembourg }\end{array}$ \\
$\begin{array}{c}\text { Public tenders hybrid } \\
\text { model }\end{array}$ & $\begin{array}{c}\text { Private (central } \\
\text { planning) }\end{array}$ & $\begin{array}{c}\text { Even infrastructure } \\
\text { deployment, merits of } \\
\text { competition }\end{array}$ & $\begin{array}{c}\text { Delays due to } \\
\text { tendering procedures, } \\
\text { binding infrastructure } \\
\text { deployment }\end{array}$ & Norway \\
\hline
\end{tabular}

\section{Methodology}

\subsection{Modelling the Agents of Electro-Mobility}

In this section, we provide an overview of the proposed methodology, focusing on the system modelling and, specifically, the interactions between the agents. In Section 3.2, we present a brief game theoretic analysis of the system and in Section 3.3 we present in detail the relevant mathematical formulation.

We consider a set of decision makers which includes the EV consumers, the private sector investors, the policy-maker and the DSO. Our modelling does not aim to simulate the agents' decision-making in full detail; the methodology is focused on the decision-making of agents relevant to be studied, effectively "projecting" the agents' decision making onto the "space" of electro-mobility. This way we circumvent the difficulty of providing an unnecessarily complex modelling of the agents' behaviour as we reduce the latter to a set of conditions that can be efficiently formulated as an equilibrium problem with equilibrium constraints. In what follows, we elaborate on how we model the behaviour of each agent (Table 2):

- The private investors generally allocate their capital in investing options that maximize the overall returns while minimizing the investment risks and considering the opportunity costs. To model their behaviour (i.e., investing in charging infrastructure), we utilize the internal rate of return (IRR) criterion to model whether the private investor will engage in the investment or not. We assume a decision threshold $R$ which represents an estimation of the opportunity cost incurred to the investor by the former choice, i.e., it represents a rate of return that the investor could achieve by investing in other choices. If the IRR of charging infrastructure investments is below that threshold, the investor has no incentive to invest. The modelling considers only the case of fast charging points and assumes exogenously that a specific part of the electricity needs is provided by other types of charging points. The price of charging services comprises of the electricity price and the tariff for recovering the capital cost of the investment. The former is exogenous to the modelling and is provided by the PRIMES energy systems model [44]. The latter is endogenously calculated based on the utilisation of the charging points assuming that the tariff is calculated using the levelized cost approach. The overall price of the charging service is capped to an upper limit and, thus, considered being regulated. We carry out sensitivity analysis around this hypothesis;

- The policy maker promotes the decarbonisation of the energy system aiming to mitigate GHG emissions in the most efficient way. Decarbonisation entails setting a target on EV penetration. The EV penetration targets are exogenous to our modelling. If the electro-mobility system fails to achieve the target without the policy maker's intervention, the latter chooses to either subsidize private investors, respecting an 
assumed subsidy budget per charging station, or to allow the DSO to deploy the EV infrastructure for some part of the modelled period (see Section 3.2). Further, we assume that the policy maker prioritizes the deployment of infrastructure by private agents (free market model) against employing a DSO model. This assumption effectively implements the EC proposal (COM (2016) 864);

- The DSO is modelled as an agent with a trivial behaviour that is activated by the policy maker and is influenced by the participation of private investors. Hence, the DSO model may not be activated in cases of high participation of private investors. Alternatively, the DSO model takes place in case of low interest from private investors that would hamper EV deployment and risk not meeting the penetration target. In this case, the DSO develops charging infrastructure that allows reaching the EV penetration targets, respecting an annual budget for charging infrastructure expenditures. It is assumed that the DSO follows a central planning approach in building charging stations and may not exceed an assumed budget for public infrastructure expenditures. The pricing of the charging service provided by the DSO is assumed to be regulated; the infrastructure costs are socially recovered via increases in electricity price;

- Consumers decide whether to purchase a conventional vehicle or an EV. They make their choice considering total cost of vehicle ownership (depending on capital, maintenance, fuel costs, and mileage), as well as perceived cost and, in particular, the lack of charging infrastructure (range anxiety). In our modelling the evolution of the capital and maintenance costs is exogenous. The rest of the cost components are endogenous. Fuel costs are calculated by adding the charging price (which are endogenous) and the electricity provided by the charging station. Range anxiety is an endogenous feature of the model as it relates to the availability of infrastructure which is the result of the choices of private investors and DSO model activation. The modelling of range anxiety draws from the PRIMES-TREMOVE model [45] and for the purposes of the present paper follows a reduced form approach.

Table 2. Taxonomy of the decision makers of the electro-mobility system considered in modelling.

\begin{tabular}{|c|c|c|}
\hline Decision Makers & Objectives and Behaviour & Notes \\
\hline Private investor & $\begin{array}{l}\text { Seeks to allocate capital in profitable } \\
\text { investing options. If charging businesses } \\
\text { display a certain level of profitability, the } \\
\text { private investor expresses interest to invest in } \\
\text { charging infrastructure. }\end{array}$ & $\begin{array}{l}\text { Private investors are risk avert and require } \\
\text { policy insurance regarding the recovery of } \\
\text { their costs. }\end{array}$ \\
\hline Consumers & $\begin{array}{l}\text { Modelled to select purchasing either an EV } \\
\text { or a conventional vehicle depending on the } \\
\text { total cost of ownership of the options and the } \\
\text { density of charging infrastructure. }\end{array}$ & $\begin{array}{l}\text { - Consumer choice is modelled to account for } \\
\text { range anxiety } \\
\text { - Consumers consider charging prices as set } \\
\text { by the operator of the charging stations }\end{array}$ \\
\hline Policy maker & $\begin{array}{c}\text { Sets concrete targets regarding the envisaged } \\
\text { penetration of EVs. Needs to ensure the } \\
\text { availability of recharging points to promote } \\
\text { uptake of EVs. }\end{array}$ & $\begin{array}{l}\text { The policy maker is assumed to prioritize } \\
\text { private deployment and operation of } \\
\text { infrastructure over public. } \\
\text { The policy maker either employs a DSO } \\
\text { model or subsidizes private investors } \\
\text { inciting them to deploy charging } \\
\text { infrastructure. }\end{array}$ \\
\hline DSO & $\begin{array}{l}\text { DSO's role in infrastructure deployment is } \\
\text { activated via a public DSO-type model only } \\
\text { if the private sector does not express interest } \\
\text { in infrastructure investments. }\end{array}$ & $\begin{array}{l}\text { - The DSO develops the charging } \\
\text { infrastructure up to the required level, also } \\
\text { respecting an annual budget on } \\
\text { investments }\end{array}$ \\
\hline
\end{tabular}




\subsection{A Game Theoretic View on the Interaction among the Agents}

We first consider the interaction between the consumers and the private investors. The actors can be seen as participating in a game which rewards cooperation between actors; value is generated by a successfully deployed electro-mobility system and shared with the actors only if both groups choose to participate, (i.e., the consumers purchase EVs and the investors develop and operate the charging infrastructure). Otherwise, if only one of the parties chooses to participate, this party suffers a loss: a consumer buying an EV would not be able to utilize his vehicle; an investor who chooses to invest while the EV penetration is at low levels would not be able to recover the investment costs. Both parties can ensure a state-of-business payoff by choosing not to get involved in the electro-mobility system. For both parties, the payoff of successful electro-mobility deployment is assumed to be greater than their state-of-business payoff. The described game is essentially the archetypal strategic setting of "stag hunt" (We note that the assumption of a regulated charging price is essential for the strategic setting we present. Should the level of charging price be part of the actors' strategies, then the resulting game would have been a bargaining game, with the charging price deciding how the value generated by a successful electromobility system is distributed among the two parties.) The two pure Nash equilibria are the following: both groups opting for electro-mobility (the payoff dominant equilibrium) and both groups averting from it (the risk dominant equilibrium or the "chicken-egg" situation).

The actors' strategic sets in our actual modelling are closed intervals instead of discrete sets. As we aim to model the decision making of a large number of consumers (i.e., Greek consumers) with idiosyncratic behaviours, for a given level of infrastructure deployment and vehicle costs, the market share of EVs purchased can be anywhere between 0 and $100 \%$ of the total new vehicle registrations. Each individual consumer has a distinct turning point on his or her decision to purchase $\mathrm{EV}$ with respect to infrastructure coverage, assuming given EV and ICE conventional vehicle costs. Under standard assumptions on the distribution of consumers' turning points, the total consumers' EV charging demand $D$ with respect to the level $i$ of infrastructure deployment can be approximated by discrete choice-based functional forms $c=D(i)$.

Likewise, the strategic set for private investors comprises of all the possible amounts of capital they invest in charging infrastructure. If the estimated IRR of charging infrastructure is below the threshold $R$, the investors choose not to invest. If the conditions are favourable enough that the estimated IRR is greater than the threshold $R$, the investors engage in the business. Once investments in recharging infrastructure start accumulating, their utilization rate may decrease, depending on the extent of the uptake of EVs. Consequently, the investors decelerate infrastructure investments down to the point where the estimated IRR is equal to $R$.

More formally, the set of strategies for consumers is defined as $C=[0, V]$ and the set of strategies for investors as $I=[0, \mathrm{U}]$. Let $c_{1}, c_{2} \in C$ and $i_{1}, i_{2} \in I$. Let $\operatorname{IRR}(c, i)$ denote the internal rate of return achieved when the EV demand is $c$ and the total infrastructure investments is $i$. Then, the preference relations over strategic profiles of the actors have the following properties:

For consumers' preference $\geq^{C}$ : For $c_{1}=D\left(i_{1}\right)$ we have $\left(c_{1}, i_{1}\right) \geq^{C}\left(c_{2}, i_{1}\right)$ for any $c_{2} \neq c_{1}$, where $D(i)$ is the EV demand function with respect to level $i$ of infrastructure investments (most preferred technology choice with respect to given infrastructure coverage). A demand greater than $c_{1}$ means that some consumers buy EVS although they do not perceived EVs to be the best choice. Similarly, a demand less than $c_{1}$ means that some consumers who prefer EVs buy conventional vehicles.

For investors' preference $\geq^{I}$ : If $\operatorname{IRR}\left(c_{1}, i_{1}\right) \geq R$ and $i_{1} \geq i_{2}$ then $\left(c_{1}, i_{1}\right) \geq^{I}\left(c_{1}, i_{2}\right)$, otherwise, if $\operatorname{IRR}\left(c_{1}, i_{1}\right)<R$, then $\left(c_{1}, i_{2}\right) \geq^{I}\left(c_{1}, i_{1}\right)$ (prefers to increase investments as long as EV business are profitable enough).

The introduction of the third player, the policy maker, completes the strategic setting of our modelling. His or her strategy set includes the following: take no action, subsidize the deployment of private charging stations up to a budget $B$, or enable the DSO to develop the 
charging infrastructure, making infrastructure investments within a budget $K$. This actor strictly prefers any outcome in which electro-mobility is successfully deployed (with respect to the specified penetration target) to any outcome in which it does not. Among outcomes of electro-mobility's success, the policy maker prefers not taking action to subsidizing the private infrastructure deployment and prefers the latter to allowing DSO to deploy the charging infrastructure.

In accordance to the above, the strategy set for the policy maker is defined as $P \subseteq[0, B] \times[0, K]$. For a strategy $(s, d) \in P, s$ denotes the subsidy per charging station given to private investors and $d$ denotes the infrastructure investments deployed by the DSO.

Extending the definition to account for the policy maker, a strategic profile is now defined as a triplet $(c, i,(s, d))$ with $c \in C, i \in I,(s, d) \in P$. The EV demand function now depends on both the DSO-deployed and the privately deployed infrastructure, i.e., $c=D(i, d)$. Likewise, the investors' estimated IRR is a function of the consumer demand, total infrastructure investments and the subsidy, i.e., $\operatorname{IRR}=\operatorname{IRR}(c, i, s, d)$.

Lastly, we note that the Nash equilibrium of the defined strategic setting can be shown to be unique and, depending on the exogenous parameters, can be any of the following: (i) the EV penetration target is achieved by the cooperated actions of consumers and private investors alone, (ii) the EV target is achieved via subsidizing privately deployed infrastructure, (iii) the EV target is achieved via a DSO-deployed infrastructure, (iv) the EV target is achieved by combined private and public investments, and (v) the EV target is not achieved. The latter situation may occur when the private sector was not incited and the budget restrictions on public investments did not allow DSO to develop the infrastructure to the required level.

\subsection{Mathematical Formulation of the Problem}

In this section, we formulate the strategic setting of Section 3.2 as a mixed complementarity problem (mcp). For simplicity, the formulation is given for a fixed year. Table 3 summarizes the set of variables and parameters of the formulation.

Table 3. The variables and parameters of the formulation.

\begin{tabular}{ccc}
\hline Name & \multicolumn{1}{c}{ Type } & Description \\
\hline$E V_{1}$ & endogenous & The number of EVs incited by deployed infrastructure when the DSO is not involved \\
\hline$E V_{2}$ & endogenous & The number of EVs incited by infrastructure, deployed either by private investors or DSO \\
\hline$E V_{e x}$ & endogenous & Existing stock of EVs inherited from previous periods. \\
\hline$T$ & exogenous & EV penetration target \\
\hline$B$ & exogenous & Upper bound of annual subsidy given per charging station ('000 euros) \\
\hline$S$ & exogenous & Annual DSO's budget for infrastructure investments ('000 euros) \\
\hline$S S f$ & exogenous & Spatial factor denoting the geographical coverage a single charging station satisfies \\
\hline$S S u p p$ & exogenous & Self-Supply factor: fraction of a single EV's demand that can be satisfied by means of charging \\
\hline$C_{\text {infra }}$ & exogenous & Amount of charging demand that is supplied by chargers at home/work \\
\hline$C_{E V}$ & exogenous & Capital cost of a charging station \\
\hline$C_{\text {conv }}$ & exogenous & total cost of ownership for EVs \\
\hline$E V_{\text {demand }}$ & exogenous & total cost of ownership for the typical ICE conventional vehicle \\
\hline$s u b s$ & endogenous & the annual charging demand of a representative EV in $\mathrm{kWh/year}$ \\
\hline$d_{1}$ & endogenous & The annual subsidy per charging station in ‘000 euros/year
\end{tabular}


Table 3. Cont.

\begin{tabular}{ccc}
\hline Name & Type & Description \\
\hline$d_{2}$ & endogenous & Total charging demand incurred by the deployment of infrastructure by private investors \\
and DSO
\end{tabular}

The formulation can be, intuitively, seen as having two phases. However, the model being formulated as a mixed complementarity problem is solved on a single shot. The use of MCP allows to use a dual variable of a constraint on the formulation of subsequent constraints. In the first phase, the model attempts to satisfy the EV penetration target allowing only private deployment of infrastructure, deciding the amount of subsidy if required. Variables with subscript 1 correspond to this phase. In the second phase, if the target is not achieved by private investments, the DSO is allowed to deploy the necessary infrastructure; the respecting variables have the subscript 2.

Let $E V_{1}$ be the number of electric vehicles and $T$ the $E V$ penetration target. The following constraint implements the component of policy maker's strategic choice that refers to subsidizing private investors. The complementary variable subs represents the subsidy per charging station, in the form of annual payments, given to private investors to incite the deployment of infrastructure. The subsidy may not exceed an exogenous budget $B$.

$$
E V_{1}-T \geq 0 \perp \text { subs } \in[0, B]
$$

Note that, since the complementary variable has an upper bound, it might be the case that in a feasible solution the inequality is not respected $\left(E V_{1}<T\right.$ and $\left.s u b s=B\right)$, meaning failure to achieve the target via a free market business model. This outcome is interpreted as the policy maker offering subsidy $B$ and, nonetheless, the private investors not being interested to invest.

The next constraint (abstractly) implements the EV demand function considering the new private investments Infr $r_{1}$ and the existing infrastructure $I n f r_{e x}$. The number of new EVs is a function of the number of charging points, charging price $\mathrm{Pr}$ and vehicle costs $C_{E V}, C_{c o n v}$, with $C_{E V}, C_{c o n v}$ being exogenous. $D$ represents demand for $E V$ and is based on discrete choice functional form. This constraint implements the consumers' choice for the first phase.

$$
E V_{1}=D\left(\text { Infr } r_{1}, \text { Infr } r_{\text {ex }}, \operatorname{Pr}, C_{E V}, C_{\text {conv }}\right) \perp E V_{1} \in \mathbb{R}
$$

The following constraint calculates the annual charging demand ( $\mathrm{kWh} /$ year) of the $E V$ fleet for the first phase. The parameter $E V_{\text {demand }}$ denotes the annual charging demand of a representative $\mathrm{EV}(\mathrm{kWh} /$ year).

$$
d_{1}=\left(E V_{1}+E V_{e x}\right) \cdot E V_{\text {demand }} \perp d_{1} \in \mathbb{R}
$$


An exogenous fraction of the total demand, denoted as $S S f$, is satisfied by home chargers based on the off-street parking capability of EV users or by charging at work.

$$
\text { SSupp }=d_{1} \cdot \operatorname{SSf} \perp \text { SSupp } \in \mathbb{R}
$$

Constraint (5) calculates the utilization $u$ (kWh/year) of charging station. Function $U$ gives the share of the demand that is satisfied by a single charging station, accounting for the spatial limitations of charging stations.

$$
u=U\left(\operatorname{Infr} r_{1}, \operatorname{Infr} r_{e x}, s f\right) \cdot\left(d_{1}-\operatorname{SSupp}\right) \perp u \in \mathbb{R}
$$

The annual cash flow NCann for a charging station is given below. The charging price is denoted by $p r$ while $v c$ and $f c$ denote the variable (e.g., electricity price) and fixed costs, respectively. The annual subsidy subs is included in the calculation. The use of MCP allows to use the dual variable subs of constraint (1) on the formulation of the annual cash flow. We note that the charging price $p r$ comprises of the electricity price and the tariff associated to the recovery of the capital cost. The latter is calculated endogenously, using the levelized cost approach and depending on the rate of utilisation $u$.

$$
N \text { Cann }=u \cdot(p r-v c)-f c+\text { subs } \perp N \text { Cann } \in \mathbb{R}
$$

The next constraint calculates the $I R R$ estimated by private investors. $C_{\text {infra }}$ denotes the capital cost of a station.

$$
\sum_{t}\left(\frac{N \text { Cann }}{(1+I R R)^{t}}\right)-C_{\text {infra }}=0 \perp I R R \in \mathbb{R}
$$

The decision making of private investors is implemented by constraint (8). Whenever $I R R$ exceeds the exogenous threshold $R$, the agent chooses to invest, i.e., Inv $v_{P A}>0$. Although the complementary variable $I n v_{P A}$ has no upper bound, it always takes finite values in a feasible solution. This is because, as $I_{n v_{P A}}$ increases beyond a certain value, IRR decreases (a) due to competition (controlled by the utilisation of the stations $U$ of constraint (5)) and (b) due to the fact that, beyond a level of infrastructure coverage, marginal demand for EVs decreases (function $D$ of constraint (2)). Thus, $I_{n} v_{P A}$ either takes a positive value and the constraint is satisfied as equality, or is zero if $I R R<R$.

$$
I R R-R \leq 0 \perp I n v_{P A} \geq 0
$$

The new infrastructure deployed by private investors for the present period is simply derived by dividing the related investment expenditures by the unit cost of the charging point:

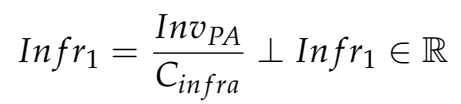

Constraints (10)-(12) refer to the DSO involvement in EV infrastructure deployment. If the target is not achieved and the private sector has not expressed interest even though the offered subsidy is at its maximum value $(s u b s=\mathrm{B})$ then, and only then, the DSO may invest in infrastructure.

Constraint (10) checks whether the target is satisfied considering the total infrastructure deployment; variable $E V_{2}$ denotes the number of EVs whose purchase was incited by total infrastructure (also see constraint (12)). If the target is not achieved, the complementary variable $I n v_{D S O}$, denoting DSO's investments, takes a positive value. In a feasible solution, either $I n v_{D S O}$ takes a sufficiently large value to achieve the EV target, or the target was achieved by private infrastructure and $I n v_{D S O}$ is equal to 0 .

$$
E V_{2}-\mathrm{T} \geq 0 \perp I n v_{D S O} \in[0, K]
$$


The number of charging station $I n f r_{2}$ of this phase is simply the total investments divided by the capital cost infra_CC of a station.

$$
I n f r_{2}=\frac{I n v_{P A}+I n v_{D S O}+I n f r_{e x}}{C_{i n f r a}} \perp I n f r_{2} \in \mathbb{R}
$$

The number EVs incited by total charging infrastructure in the second phase is derived by the following constraint:

$$
E V_{2}=D\left(I n f r_{2}, I n f r_{\text {ex }}, \operatorname{Pr}, C_{E V}, C_{\text {conv }}\right) \perp E V_{2} \in \mathbb{R}
$$

In the actual model, the mathematical program is solved iteratively for each time period, assuming 1-year time steps, inheriting the state of the electro-mobility system that resulted from the solution of the previous years. The inherited state concerns the existing stock of EVs and the already developed charging infrastructure and affects the utilization and profitability of new infrastructure, and the market penetration of new EVs. Lastly, we assume annual targets on EV penetration-the cumulative EV stock should amount to the desired level of penetration at the end of the modelled period, assuming it was feasible to achieve each year's target.

\section{Scenarios and Results: The Evolution of Electro-Mobility in Greece for the 2021-2030 Period}

\subsection{Background}

This section outlines the proposed methodology, presented in Section 3. We display the functionality of the proposed system modelling by applying it to the Greek case. The 2021-2030 decade is critical for ensuring transport embarks on a decarbonisation pathway by 2050. Recent plans by the Greek government [46] envisage reaching a deployment of approximately $10 \%$ of EVs in the total fleet of cars by 2030 (i.e., around 500,000 EVs), in view of the 2030 Energy and Climate target. The vast majority of the envisaged EV sales are expected to be small-sized cars. Yet, the current deployment of recharging points and the associated EV sales are negligible in Greece. To motivate EV sales and development of recharging points, Greece has adopted the EC proposal by retaining a DSO model as a shortterm solution [34] and aiming at the adoption of a free market model for infrastructure deployment in the medium-term.

Given the above, the quantification of scenarios carried out in this research paper is built around the assumption that the EV deployment will need to reach approximately $10 \%$ of the total fleet in 2030. The scenarios explore the factors which influence the transition from a public DSO to a private free market model, considering alternative framework conditions (e.g., costs of EVs, costs of charging points), as well as potential subsidisation of the capital costs of the charging points.

In the following, we present the underlying assumptions and the description of the scenarios. Afterwards, we present the model results for scenarios and sensitivities we carry out.

\subsection{Assumptions and Description of Scenarios}

For our analysis, we consider three different cases for the evolution of EV purchase costs and infrastructure capital costs. The purchasing costs of EVs draw from literature and follow a central, an optimistic and a pessimistic trajectory, using assumptions from literature. We define a set of nine scenarios corresponding to the possible combinations of cost assumptions (see the scenario names and definitions in Table 4). The assumed costs are presented in Tables 5 and 6 . 
Table 4. Qualitative specifications of the nine scenarios.

\begin{tabular}{ccc}
\hline Scenario Name & EV Purchase Cost & Charging Station Capital Cost \\
\hline Low EV-Low Ch.Point & Low Cost (optimistic) & Low Cost (optimistic) \\
Low EV-Mid Ch.Point & Low Cost (optimistic) & Central Cost \\
Low EV-High Ch.Point & Low Cost (optimistic) & High Cost (pessimistic) \\
Mid EV-Low Ch.Point & Central Cost & Low Cost (optimistic) \\
Mid EV-Mid Ch.Point & Central Cost & Central Cost \\
Mid EV-High Ch.Point & Central Cost & High Cost (pessimistic) \\
High EV-Low Ch.Point & High Cost (pessimistic) & Low Cost (optimistic) \\
High EV-Mid Ch.Point & High Cost (pessimistic) & Central Cost \\
High EV-High Ch.Point & High Cost (pessimistic) & High Cost (pessimistic) \\
\hline
\end{tabular}

Table 5. Assumptions on the evolution of medium sized EVs purchasing cost (in euros).

\begin{tabular}{cccc}
\hline Euros & $\mathbf{2 0 2 0}$ & $\mathbf{2 0 2 5}$ & $\mathbf{2 0 3 0}$ \\
\hline Low Cost & & 27,000 & 23,000 \\
Moderate Cost & 31,000 & 28,000 & 24,000 \\
High Cost & & 29,000 & 27,000 \\
\hline
\end{tabular}

Table 6. Assumptions on the capital cost in euros of L3 Charging Stations (in euros).

\begin{tabular}{cccc}
\hline Euros & $\mathbf{2 0 2 0}$ & $\mathbf{2 0 2 5}$ & $\mathbf{2 0 3 0}$ \\
\hline Low Cost & & 36,500 & 28,000 \\
Moderate Cost & 44,000 & 40,000 & 35,000 \\
High Cost & & 42,500 & 40,000 \\
\hline
\end{tabular}

The rest of the assumptions are common and include the following:

- The price of electricity, which is the variable cost of a charging station and affects the fuel cost of EVs draws from the PRIMES model [44] and ranges from 0.163 euros $/ \mathrm{kWh}$ in 2021 to 0.175 euros $/ \mathrm{kWh}$ in 2030 . The remuneration of the capital cost of the charging points is calculated endogenously in the model based on the levelized cost of infrastructure. The charging price is assumed to be capped at 0.32 euros $/ \mathrm{kWh}$ to prevent overcharging of EV users;

- The share of demand that is self-supplied by means of home charging is assumed to range from around $75 \%$ in the start of the 2021-2030 decade to around $70 \%$ in 2030, drawing from [47];

- The maximum annual subsidy per charging station is assumed to be 4000 euros. Recall that, in our modelling, the actual annual subsidy is endogenously derived each year to ensure a certain level of profitability for private investors;

- The annual budget for public infrastructure investment is assumed to be 15 million euros. Public infrastructure investments are made whenever DSO model deploys. In this case, the amount of investments depends on the infrastructure coverage required to achieve the desired level of EV penetration, following a central planning approach;

- The IRR decision threshold for private investors to engage in the charging infrastructure development is assumed to be $5 \%$. We carry out sensitivity analysis on this assumption;

- All the techno-economic assumptions on the competing vehicle technologies, apart from the purchase cost of EVs, are common among the scenarios. These assumptions include vehicle mileage, fuel consumption, maintenance and insurance costs, and vehicle economic lifetime. For the competing fuel technologies, we assume two representative vehicles: a medium-sized gasoline car and a medium sized EV;

- Lastly, for public infrastructure we consider L3 DC fast recharging stations assuming a typical charging power of $50 \mathrm{KW}$. 
Table 5 presents the three assumed cases for the evolution of EV purchase costs and Table 6 presents the respecting cases for the evolution of charging station capital costs for the 2021-2030 period. For the year 2020, we assume the same costs for EVs and charging points across the scenarios. For the intermediate years (2021-2024 and 2026-2029), we have assumed a linear interpolation of the costs

\subsection{Model Results}

\subsubsection{Penetration of EVs}

The penetration of EVs in all scenarios in the first half of the 2021-2030 decade displays only marginal variation (see Table 7). In all scenarios, in 2021 the EV fleet consists of around 2-3000 vehicles with only small differences among the scenarios due to the common scenario assumption (i.e., costs of cars and charging points). The fleet of EVs reaches approximately 143,000 vehicles in 2025 with small variations among the scenarios (which is justified to a certain extent by the relatively small variations in the cost assumptions in 2025). This result is also driven by the fact that the DSO model is employed in the first years, as will be presented further on this section, which develops infrastructure based on planned coverage and applies common regulated charging prices.

Table 7. Total stock of EVs in Greece in '000 vehicles.

\begin{tabular}{|c|c|c|c|}
\hline Scenario & 2021 & 2025 & 2030 \\
\hline Low EV-Low Ch.Point & 2.7 & 143 & 549 \\
\hline Low EV-Mid Ch.Point & 2.6 & 143 & 535 \\
\hline Low EV-High Ch.Point & 2.5 & 143 & 527 \\
\hline Mid EV-Low Ch.Point & 2.6 & 143 & 530 \\
\hline Mid EV-Mid Ch.Point & 2.5 & 143 & 518 \\
\hline Mid EV-High Ch.Point & 2.5 & 142 & 511 \\
\hline High EV-Low Ch.Point & 2.5 & 143 & 504 \\
\hline High EV-Mid Ch.Point & 2.4 & 142 & 493 \\
\hline High EV-High Ch.Point & 1.8 & 138 & 479 \\
\hline
\end{tabular}

By contrast, the second half of the 2021-2030 decade displays a greater variation in EV penetration. The Low EV-Low Ch.Point scenario records the highest EV penetration (around 548,600 EVs) while the lowest EV penetration takes place in the High EV-High Ch.Point $(479,000$ EVs). The differences in the evolution of EV and charging station capital costs are enlarged towards the end of the studied period and, thus, have a greater impact on EV penetration compared to the first half of the decade. In addition, in the 2025-2030 period, the private sector becomes more active in infrastructure deployment (also see Section 4.3.2). As the infrastructure investments of the private sector react with charging demand in a feedback relationship, the private model causes rebound effects on the EV penetration in scenarios with more optimistic assumed costs. We note that, even in 2030, the EV fleet variation is within $10 \%$ of the $500,000 \mathrm{EVs}$ target. This is the result of policy action taken to ensure the satisfaction of the target; in scenarios with less favourable cost assumptions: (i) the DSO model is employed for a longer period to help achieve a sufficient level of EV penetration and, thus, charging demand before the private agents start investing and (ii) the subsidization of private agents is stronger in the scenarios with less favourable infrastructure capital cost (see following section).

\subsubsection{Deployment of Private Investments in Charging Infrastructure Development}

The total number of available charging stations for 2021, 2025, and 2030 is presented in Table 8. It is generally observed that in all scenarios the number of charging stations follows the increasing trend of the EV fleet. Table 9 presents the deployment of the private investment (i.e., the share of publicly available charging stations deployed using private funds in the total number of available charging stations). All scenarios indicate an ever- 
growing involvement of the private investors in the EV recharging infrastructure business towards the end of the decade 2021-2030.

Table 8. Total available charging stations per time period.

\begin{tabular}{cccc}
\hline Scenario & $\mathbf{2 0 2 1}$ & $\mathbf{2 0 2 5}$ & $\mathbf{2 0 3 0}$ \\
\hline Low EV-Low Ch.Point & 79 & 1719 & 5245 \\
Low EV-Mid Ch.Point & 78 & 1708 & 4924 \\
Low EV-High Ch.Point & 78 & 1695 & 4746 \\
Mid EV-Low Ch.Point & 79 & 1765 & 5066 \\
Mid EV-Mid Ch.Point & 78 & 1757 & 4772 \\
Mid EV-High Ch.Point & 78 & 1751 & 4599 \\
High EV-Low Ch.Point & 79 & 1841 & 4822 \\
High EV-Mid Ch.Point & 78 & 1832 & 4541 \\
High EV-High Ch.Point & 73 & 1822 & 4312 \\
\hline
\end{tabular}

Table 9. Share of charging stations deployed by the private sector in the total available charging stations.

\begin{tabular}{cccc}
\hline Scenario & $\mathbf{2 0 2 1}$ & $\mathbf{2 0 2 5}$ & $\mathbf{2 0 3 0}$ \\
\hline Low EV-Low Ch.Point & & $34 \%$ & $85 \%$ \\
Low EV-Mid Ch.Point & & $34 \%$ & $84 \%$ \\
Low EV-High Ch.Point & & $33 \%$ & $83 \%$ \\
Mid EV-Low Ch.Point & \multirow{2}{*}{$\%$} & $35 \%$ & $84 \%$ \\
Mid EV-Mid Ch.Point & & $35 \%$ & $83 \%$ \\
Mid EV-High Ch.Point & & $31 \%$ & $81 \%$ \\
High EV-Low Ch.Point & $36 \%$ & $82 \%$ \\
High EV-Mid Ch.Point & $32 \%$ & $80 \%$ \\
High EV-High Ch.Point & $25 \%$ & $76 \%$ \\
\hline
\end{tabular}

Interestingly, while in 2025 the scenarios with pessimistic EV cost assumptions (i.e., High) show a higher number of charging stations, the picture changes in 2030 when we observe a higher number of total available charging stations in the scenarios with the optimistic cost assumptions (i.e., Low). Such development is attributed to the fact that in the first half of the 2020-2030 decade, infrastructure is deployed for the most part by the DSO, driven mainly by the need to meet the policy target rather than for profitability reasons. In the second half of the decade, we notice that the private model turns out to be the prevailing model for infrastructure deployment. This is the result of the development of a critical mass of charging points (thanks to the DSO engagement in the early years), implying an adequate utilisation of the charging points and ensuring profitability. The assumed cost reductions in all scenarios are also a critical factor for such development. The consumers also tend to purchase more EVs as a result of the decreasing EV costs and the reduction in the range anxiety (due to the development of the critical mass of charging points). Especially, in the case of the optimistic cost assumptions, we observe higher EV penetration resulting in higher utilization of infrastructure, further inciting the private sector engagement.

The scenarios project a relatively similar success for the electro-mobility system and the private infrastructure model at the end of the 2021-2030 period. The policy intervention via the initial DSO-model deployment and the subsidization of private investments mitigates to some extent the higher infrastructure costs and the low EV penetration (due to the higher costs in the early years). Evidently, the level of intervention required differs significantly among the scenarios. The annual subsidy per private charging station from 2024 to 2028 is presented in Table 10. In all scenarios, before 2024, the low infrastructure utilization prevents the private investors from entering the infrastructure market. Until 2023 all the charging stations are publicly developed via the DSO model. In 2024, with the help of subsidization, the private investors are involved in infrastructure deployment for the first 
time. In 2024 the subsidy that private stations require is close to the maximum available budget per charging point of 4000 euros. The subsidization is gradually decreased in later years. In the Low EV-Low Ch.Point (most optimistic) scenario the private charging stations stop needing subsidy as until 2026. In contrast, in the High EV-High Ch.Point (most pessimistic) scenario the private stations still require some subsidization, up to 2028, to ensure an acceptable level of profitability.

Table 10. Annual subsidy given to private agents per charging station in euros.

\begin{tabular}{|c|c|c|c|c|c|}
\hline Scenario & 2024 & 2025 & 2026 & 2027 & 2028 \\
\hline Low EV-Low Ch.Point & 3700 & 2600 & 1200 & 0 & 0 \\
\hline Low EV-Mid Ch.Point & 3900 & 2800 & 1500 & 100 & 0 \\
\hline Low EV-High Ch.Point & 4000 & 3000 & 1600 & 200 & 0 \\
\hline Mid EV-Low Ch.Point & 3800 & 2700 & 1400 & 200 & 0 \\
\hline Mid EV-Mid Ch.Point & 4000 & 3000 & 1700 & 400 & 0 \\
\hline Mid EV-High Ch.Point & 4000 & 3200 & 1900 & 600 & 0 \\
\hline High EV-Low Ch.Point & 3900 & 3000 & 1800 & 600 & 0 \\
\hline High EV-Mid Ch.Point & 4000 & 3200 & 2000 & 900 & 0 \\
\hline High EV-High Ch.Point & 4000 & 4000 & 2700 & 500 & 300 \\
\hline
\end{tabular}

The subsidization of the privately deployed recharging points and the DSO employment is found to increase the government bill. Table 11 presents the cumulative government expenditures on the infrastructure investments made via the DSO model and the subsidies given to support infrastructure deployment by private agents. Naturally, the expenditure is greater in scenarios with higher infrastructure costs. This is not only because the costs of the charging points, per se, are higher, but also because the private investors are more reluctant to invest. In particular, the largest part of the total government expenditures is found to be necessary in the period up to 2025, when the DSO model is largely employed. For the period after 2025 government expenditures concern, for the most part, the subsidization of private investors which requires less capital compared to the public development of infrastructure. Towards the end of the period, the deployment of recharging infrastructure takes place without further policy support and does not require additional expenditures from the government.

Table 11. Cumulative government expenditures for infrastructure investments and subsidies in million.

\begin{tabular}{cccc}
\hline Scenario & $\mathbf{2 0 2 1}$ & $\mathbf{2 0 2 5}$ & $\mathbf{2 0 3 0}$ \\
\hline Low EV-Low Ch.Point & 3.5 & 52.7 & 53.7 \\
Low EV-Mid Ch.Point & 3.4 & 54.2 & 55.6 \\
Low EV-High Ch.Point & 3.4 & 55.9 & 57.6 \\
Mid EV-Low Ch.Point & 3.5 & 53.7 & 55.3 \\
Mid EV-Mid Ch.Point & 3.4 & 55.3 & 57.4 \\
Mid EV-High Ch.Point & 3.4 & 58.6 & 60.9 \\
High EV-Low Ch.Point & 3.5 & 55.5 & 58.1 \\
High EV-Mid Ch.Point & 3.4 & 59.6 & 62.7 \\
High EV-High Ch.Point & 3.2 & 71.6 & 75.8 \\
\hline
\end{tabular}

Table 12 presents the endogenously calculated charging price for using the infrastructure; a part of the charging price includes the tariff set by the investors to recuperate their capital cost. As presented in the assumptions of the modelling implementation, the latter is calculated to be equal to the levelized cost of the use of the charging infrastructure. We acknowledge though that, sometimes, this practice may differ from reality, especially in the early years of EV deployment when the demand for charging might be low. In such cases, regulated prices might apply to avoid deterring private investors from entering the market and EV users be discouraged from high charging prices. We carry out a sensitivity 
analysis on the charging price assumptions, however, more research is needed on this topic. As confirmed by the results, the tariff for recovery of the capital cost of charging point is greater in scenarios with higher infrastructure capital costs. The levelized costs decrease in 2030 due to assumed reduction in infrastructure costs and higher utilisation rates of the infrastructure. The charging tariff, however, increases as it includes the price of electricity which, according to our assumptions, is approximately 0.16 euros $/ \mathrm{kWh}$ and 0.175 euros/kWh in 2025 and 2030, respectively.

Table 12. Charging price in euro/kWh in 2025 and 2030.

\begin{tabular}{ccccc}
\hline Scenario & $\begin{array}{c}\text { Tariff for Recovery of the } \\
\text { Capital Cost of Charging Point }\end{array}$ & $\begin{array}{c}\text { Total Charging Tariff (Incl. } \\
\text { Electricity Price) }\end{array}$ \\
\hline & $\mathbf{2 0 2 5}$ & $\mathbf{2 0 3 0}$ & $\mathbf{2 0 2 5}$ & $\mathbf{2 0 3 0}$ \\
\hline Low EV-Low Ch.Point & 0.131 & 0.114 & 0.281 & 0.289 \\
Low EV-Mid Ch.Point & 0.137 & 0.126 & 0.287 & 0.301 \\
Low EV-High Ch.Point & 0.142 & 0.137 & 0.292 & 0.312 \\
Mid EV-Low Ch.Point & 0.133 & 0.116 & 0.283 & 0.291 \\
Mid EV-Mid Ch.Point & 0.141 & 0.131 & 0.291 & 0.306 \\
Mid EV-High Ch.Point & 0.147 & 0.142 & 0.297 & 0.317 \\
High EV-Low Ch.Point & 0.136 & 0.119 & 0.286 & 0.294 \\
High EV-Mid Ch.Point & 0.146 & 0.136 & 0.296 & 0.311 \\
High EV-High Ch.Point & 0.152 & 0.137 & 0.302 & 0.312 \\
\hline
\end{tabular}

\subsection{Sensitivity Analysis}

The scenario analysis considered nine combinations of alternative trajectories for the costs of EVs and the charging points. To complement the scenario analysis, we present a sensitivity analysis on key elements which are expected to influence the model results. The aim of the sensitivity analysis is to quantify how the recharging infrastructure deployment is influenced by different thresholds of profitability criteria for private investors and policy support. In particular, we carry out sensitivity analysis with varying:

- charging prices of the private investors, by assuming that the capital cost recovery is based on pre-defined regulated prices;

- values of IRR decision threshold for private investors to engage in the recharging infrastructure development business;

- levels of the maximum available budget (per charging point) for subsidising private investors.

4.4.1. The Effects of Different Levels of Regulated Charging Tariffs on the Infrastructure Deployment

A sensitivity analysis was performed to assess the implementation of regulated charging prices. On the one hand, applying regulated prices may attract private investors to develop private charging points as it reduces the associated investment risk to a certain extent; on the other hand, regulated prices will also ensure affordable price for consumers to use charging services for their EVs. We use the central scenario Mid EV-Mid Ch.Point, as a starting point to quantify two new scenarios, namely: The Low Ch.Price and the High Ch.Price scenarios, which assume regulated charging prices of 0.32 and 0.22 euros $/ \mathrm{kWh}$, respectively. We note that in the Mid EV-Mid Ch.Point scenario the charging price is approximately 0.29 euros/ $\mathrm{kWh}$ (see Table 12).

Table 13 compares the cumulative deployment of charging stations and the respective share of private investments in the total installations in 2030 of the Mid EV-Mid Ch.Point, Low Ch.Price, and High Ch.Price scenarios. 
Table 13. Number of charging stations and respective share deployed by the private sector in 2030 .

\begin{tabular}{ccc}
\hline Scenario & $\begin{array}{c}\text { Cumulative Number of } \\
\text { Stations }\end{array}$ & $\begin{array}{c}\text { Share of Stations Developed } \\
\text { by Private Agents }\end{array}$ \\
\hline Mid EV-Mid Ch.Point & 4772 & $83 \%$ \\
High Ch.Price & 4985 & $89 \%$ \\
Low Ch.Price & 4547 & $77 \%$ \\
\hline
\end{tabular}

Both the number of stations and the degree of private sectors' involvement in the two sensitivity scenarios suggest that a higher charging price positively affects the deployment of infrastructure and the success of a private model for EV charging. The higher prices assumed relative to the central case are found to positively influence investors. These, together with the increased investments in charging points, are found to positively influence demand (despite the increase in the prices of the services) as the range anxiety factor is diminished. The increased profitability of charging businesses leads the private sector to deploy $89 \%$ of the 4985 stations in 2030 in scenario High Ch.Price. By contrast, 4547 fast charging stations are built by 2030 in scenario Low Ch.Price, lower than the 4772 stations of the Mid EV-Mid Ch.Point scenario and about $77 \%$ of the stations are deployed via private investments.

Similar results are also found when comparing the EV fleet evolution. The higher charging price also results in greater penetration of EVs in the High Ch.Price scenario (approximately 530,000 EVs in 2030) compared to the Mid EV-Mid Ch.Point, while in the Low Ch.Price scenarios approximately 505,000 vehicles are found to penetrate the market by 2030 . The increased charging price for public charging only marginally affected the EV user variable costs, as a large part of charging demand is satisfied by home charging. The variable costs (i.e., charging costs) account for a relatively small fraction of the total cost of ownership. The larger infrastructure coverage of the High Ch.Price scenario mitigates the range anxiety to a significant extent, leading to a more favourable perceived cost of EVs compared to the rest scenarios.

\subsubsection{Sensitivity Analysis on Private Investors' IRR}

A second sensitivity analysis is performed to evaluate how the private investments in the recharging infrastructure business are influenced when investors expect higher returns on their investment. Higher investment returns are also associated with the opportunity cost of the businesses. The common assumption, presented in the scenarios above, is that investors engage when the expected IRR of their investment exceeds $5 \%$. As part of the sensitivity analysis, we assume greater values for the IRR decision threshold of private investors, which translates to a greater reluctance of the private sector to participate in the deployment of infrastructure.

We define two additional sensitivity scenarios based, again, on scenario Mid EV-Mid Ch.Point: the scenario IRR_8, which assumes an 8\% IRR decision threshold for private investors, and scenario IRR_12, which assumes a 12\% decision threshold. The 8 and 12\% IRR thresholds selected for the present sensitivity analysis were based on [48], on the financial viability of low-power charging stations in Greece, which suggests an IRR of around 10\%. The 5\% IRR decision threshold assumed in the 9 scenarios of Section 4.3 was selected based on the past decade's experience on solar panel investments in Greece. Table 14 shows the cumulative number of charging stations, the respective share developed by the private sector and the total EV fleet in 2030 .

The increased decision threshold makes investors more reluctant to invest in infrastructure. In IRR_8 and IRR_12 scenarios the private sector involvement in infrastructure deployment in 2030 is less than that of scenario Mid EV-Mid Ch.Point; overall, 75 and $61 \%$ of total charging stations are privately deployed in IRR_8 and IRR_12, respectively, compared to the $83 \%$ share in the Mid EV-Mid Ch.Point scenario. 
Table 14. Share of charging stations deployed by the private sector in 2030.

\begin{tabular}{cccc}
\hline Scenario & $\begin{array}{c}\text { Cumulative Number } \\
\text { of Stations }\end{array}$ & $\begin{array}{c}\text { Share of Stations Developed by } \\
\text { Private Agents }\end{array}$ & EV Fleet \\
\hline Mid EV-Mid Ch.Point & 4772 & $83 \%$ & 518.2 \\
IRR_8 & 4186 & $75 \%$ & 491.9 \\
IRR_12 & 3408 & $61 \%$ & 465.7 \\
\hline
\end{tabular}

In addition, the greater IRR decision threshold of IRR_8 and IRR_12 negatively affect the total number of EVs and the charging stations built by 2030. We find that as the expectations for the investment returns increase, the deployment of private investments decreases. This is driven by the fact that to achieve an IRR of $12 \%$, high utilisation of the charging points for long periods of time is needed. Interestingly, we observe that the share of stations developed by private investors reaches $61 \%$ of the total installations in 2030 in the scenario with an IRR of $12 \%$, in contrast with the scenario with an IRR of $5 \%$ in which the equivalent share is $83 \%$. Moreover, the total EV fleet in the IRR_12 scenario is well below 500,000 vehicles. This is the result of the failure to achieve the penetration target in some years of the modelled period; in IRR_12 the private actors have lesser engagement compared to the other scenarios and the public investments fail to achieve the needed infrastructure coverage due to budget limitations.

\subsubsection{Sensitivity Analysis on the Available Budget}

The third part of the sensitivity analysis aims to assess how the assumed subsidy budget affects the decision making of private investors and the success of a private model for infrastructure. The annual subsidy for the private deployment and operation of fast charging stations, as observed in the results of Section 4.3, acted primarily as a support for the transition period from a DSO model to a private model that occurs in the mid-term of the studied period. This part of the sensitivity analysis aims to answer whether a different subsidy budget can accelerate or delay the participation of private investors.

For this purpose, we define two new scenarios: the scenario High Sub, which assumes a 5000 budget for subsidies and the scenario Low Sub, which assumes a 2000 budget. Both scenarios are based, once again, on the assumptions of the Mid EV-Mid Ch.Point scenario. Keep in mind that the scenario Mid EV-Mid Ch.Point assumes an annual budget of 4000 euros. Table 15 presents the total charging stations built in 2021, 2025, and 2030 for the three scenarios and Table 16 shows the respective share of charging stations that is deployed by private investors.

Table 15. Total available charging stations per time period for the three scenarios.

\begin{tabular}{cccc}
\hline Scenario & $\mathbf{2 0 2 1}$ & $\mathbf{2 0 2 5}$ & $\mathbf{2 0 3 0}$ \\
\hline Mid EV-Mid Ch.Point & & 1757 & 4772 \\
High Sub & 78 & 1803 & 4799 \\
Low Sub & & 1690 & 4727 \\
\hline
\end{tabular}

Table 16. Share of charging stations deployed by the private sector in the total available charging stations per time period.

\begin{tabular}{cccc}
\hline Scenario & $\mathbf{2 0 2 1}$ & $\mathbf{2 0 2 5}$ & $\mathbf{2 0 3 0}$ \\
\hline Mid EV-Mid Ch.Point & $0 \%$ & $35 \%$ & $83 \%$ \\
High Sub & & $52 \%$ & $88 \%$ \\
Low Sub & & $0 \%$ & $71 \%$ \\
\hline
\end{tabular}

Model results show that, while higher and lower subsidy budget leads to accelerated and delayed participation of the private sector, respectively, the total infrastructure deployed, especially towards the end of the period, is only marginally affected. This finding 
is consistent with the observation that subsidies are needed mainly in the mid-term and are irrelevant towards 2030. As the infrastructure is deployed via a DSO model, whenever the private investors are not incited to invest, in later years (i.e., 2027-2030) the investors find themselves in a similar state of the electro-mobility system and, thus, resort to similar decisions. This explains smaller variation in the share of private infrastructure in 2030 compared to 2025.

\section{Conclusions}

Electric vehicles present a key solution to decarbonize the passenger car segment; the EU strategy for the mitigation of GHG emissions in transport foresees a widespread adoption of EVs. A key barrier to the wider uptake of EVs is the lack of charging infrastructure, which poses mobility limitations to the EV users and causes range anxiety. In turn, the low uptake of electro-mobility prevents investors from engaging in the recharging infrastructure development business. This "chicken-egg" problem can be solved by strategically developing charging stations using public funds to achieve the deployment of a critical mass of infrastructure, which then will attract private investors.

The scientific contribution of the present work lies on the proposal and application of a model of the electro-mobility system which simulates the interplay between the penetration of EVs and the coverage of charging infrastructure, focusing on the transition from an initial public model for infrastructure deployment to a private model, which ensures the successful participation of the private sector. The aim of the work is to assess the impact of multiple factors on the evolution of EVs, including EV purchase costs, charging stations' capital costs, charging price, policy support via subsidies, and variations in investors behaviour.

The proposed methodology is applied on the case study of Greece, quantifying the impacts of the aforementioned factors on the penetration of EVs and the rollout of charging infrastructure. The national Greek objectives refer to an uptake of $10 \%$ EVs in the total fleet of cars by 2030, when currently the national EV sales are negligible. Greece represents a typical example of a country with ambitious EV targets for 2030, with limited development of recharging infrastructure up to now. This is why we think this work is policy relevant also for other countries with limited infrastructure development until today.

\subsection{Policy Implications}

The policy implications for Greece reveal that a DSO-type model needs to be employed early in the 2021-2030 period and be replaced by a private model for charging infrastructure with the help of subsidies in the mid-term. DSO deployment is based on public funds, which we acknowledge to be one form of governmental support to developing the charging infrastructure.

Another form of governmental support, which we consider in this paper, is via subsidizing private investors in entering the market. Price subsidization of the charging points deployed by private investors is necessary during a transition period from a DSO to a private business model. The transition period for Greece is found to take place around 2025. Providing higher subsidies to the private investors can accelerate the transition to private business model in Greece. A third form of governmental support is assuming regulated tariffs, which allow private investors to sufficiently recover the initial investment. In such cases, private investors find the recharging business more secure, thus attractive, and engage early in the 2020-2030 decade. We find that such development leads to an earlier accumulation of a critical mass of charging points, which quickly mitigates the consumers' range anxiety.

The analysis finds that the private model is deployed without the need for further policy help, when approaching 2030, leading to the successful rollout of EVs. The main reason for this is that a critical mass of charging points and EVs has been already developed, which means infrastructure is sufficiently used and range anxiety is dropping. We suggest 
that the complete transition to the private business model is the solution to the "chickenegg" problem.

Undoubtedly, framework conditions such as the dropping costs of EV and of charging points can have a noticeable effect in the transition from public to private business models. Lower infrastructure costs result in earlier participation of private investors, increased profitability of charging businesses and less need for subsidization. Similarly, lower EV purchasing costs result in stronger EV penetration, which affects infrastructure deployment in a feedback relationship.

The key policy proposal is that the infrastructure should be deployed in the first years of the decade with the support of public funds to ensure the penetration of a critical mass of EVs. The increased demand for charging services and use of infrastructure, combined with sufficient amount of subsidizations, should encourage, in the mid-term, the participation of the private sector so as to let, eventually, the market forces lead the evolution of the system. Subsidizing the private investors to deploy charging points can be assessed after a critical mass of publicly-deployed charging points has been installed, since such an analysis needs to consider the opportunity costs of the public funds.

An interesting question arises as to whether the analysis can be applied to the whole of the EU. This is critical considering the uneven distribution of electricity recharging infrastructure among the EU countries, so far. In our view, the conclusions of this paper ought to be generalised to the whole EU and to individual EU countries in a careful way and considering a number of specificities. Statistics show varying EV deployment patterns across EU Member States; higher EV deployment has been recorded in countries with high household disposable income. The available household budget has been an important criterion for alleviating the cost of EVs barrier until now. In addition, government support (in the form of purchasing price subsidies) has also focused on reducing the cost barrier for EVs. So far, the government support for EV adoption is quite different among EU countries. The development of the charging infrastructure in the EU has been based on a mix of private and public funds. The paper concludes that public funding may play an important role in the initial deployment of EVs charging infrastructure; this conclusion seems to be more relevant in countries with low EV market uptake, low charging infrastructure development, and a relatively low household disposable income.

\subsection{Limitations and Scope for Further Research}

We acknowledge a number of limitations in the present study, which need to be addressed in future research.

A limitation of the study is that it considers the case of fast-charging points and not the possibility of semi-fast public charging points. The analysis considers only a single type of publicly available charging points (i.e., a fast DC recharging point of approximately $50 \mathrm{~kW}$ ). This is because in Greece short driving distances mainly for commuting purposes may not require the use of the entire batter power, which the car owner can charge at their residence. Future research thus needs to assess the necessary investments in the development of other types of charging points based on their charging power (semi-fast and ultra-fast DC charging points).

The representation of the policy support can be refined in the future. In this paper, for the deployment of infrastructure we assumed policy support schemes separately for private investors, charging points developed by DSO and charging prices. A more refined approach could consider a total amount of available public funds to be optimally allocated to ensure the timely roll-out of EV charging infrastructure. Moreover, we considered the tariff set on charging points to be equal to the levelized cost of using the charging infrastructure. We acknowledge though that, sometimes, this practice may differ from reality, especially in the early years of EV deployment when demand for charging might be low.

In this study the car manufacturers are not represented as a separate entity, interacting with the other agents of electro-mobility ecosystem. Considering them in future work 
would allow further exploring different business models, such as in [49], where the decision over the cooperation between EV manufacturers and charging station operators leads to different overall profits, market shares, and vehicle attributes.

Author Contributions: Conceptualization, P.S. and P.C.; methodology, P.S. and P.C.; software, S.S. and Y.M.; validation, P.S. and P.C.; formal analysis, S.S. and Y.M.; investigation, S.S., P.S. and Y.M.; resources, P.S.; data curation, S.S. and Y.M.; writing-original draft preparation, S.S. and Y.M.; writing—review and editing, P.S.; visualization, Y.M..; supervision, P.S. and P.C.; project administration, P.S.; funding acquisition, P.C. All authors have read and agreed to the published version of the manuscript.

Funding: This research was funded by the European Union's Horizon 2020 research and innovation programme under grant agreement No 730403 "Innovation pathways, strategies and policies for the Low-Carbon Transition in Europe (INNOPATHS)".

Acknowledgments: This paper has received funding from the European Union's Horizon 2020 research and innovation programme under grant agreement No 730403 "Innovation pathways, strategies and policies for the Low-Carbon Transition in Europe (INNOPATHS)". The content of this paper does not reflect the official opinion of the European Union. Responsibility for the information and views expressed herein lies entirely with the author(s). The authors would like to thank the anonymous reviewers for their comments which greatly improved the manuscript.

Conflicts of Interest: The authors declare no conflict of interest.

\section{References}

1. EC. A Clean Planet for all A European Strategic Long-Term Vision for a Prosperous, Modern, Competitive and Climate Neutral Economy: In-Depth Analysis in Support of the Commission Communication COM(2018) 773. 2018. Available online: https:/ / knowledge4policy.ec.europa.eu/publication/depth-analysis-support-com2018-773-clean-planet-all-europeanstrategic-long-term-vision_en (accessed on 21 February 2021).

2. Connolly, D.; Mathiesen, B.V.; Ridjan, I. A comparison between renewable transport fuels that can supplement or replace biofuels in a 100\% renewable energy system. Energy 2014, 73, 110-125. [CrossRef]

3. McCollum, D.; Krey, V.; Kolp, P.; Nagai, Y.; Riahi, K. Transport electrification: A key element for energy system transformation and climate stabilization. Clim. Chang. 2014, 123, 651-664. [CrossRef]

4. Pietzcker, R.C.; Longden, T.; Chen, W.; Fu, S.; Kriegler, E.; Kyle, P.; Luderer, G. Long-term transport energy demand and climate policy: Alternative visions on transport decarbonization in energy-economy models. Energy 2014, 64, 95-108. [CrossRef]

5. Bosetti, V.; Longden, T. Light duty vehicle transportation and global climate policy: The importance of electric drive vehicles. Energy Policy 2013, 58, 209-219. [CrossRef]

6. Zhang, Q.; Li, H.; Zhu, L.; Campana, P.E.; Lu, H.; Wallin, F.; Sun, Q. Factors influencing the economics of public charging infrastructures for EV-A review. Renew. Sustain. Energy Rev. 2018, 94, 500-509. [CrossRef]

7. Sierzchula, W.; Bakker, S.; Maat, K.; Wee, B. The influence of financial incentives and other socio-economic factors on electric vehicle adoption. Energy Policy 2014, 68, 183-194. [CrossRef]

8. Statharas, S.; Moysoglou, Y.; Siskos, P.; Zazias, G.; Capros, P. Factors Influencing Electric Vehicle Penetration in the EU by 2030: A Model-Based Policy Assessment. Energies 2019, 12, 2739. [CrossRef]

9. Dong, J.; Lin, Z. Within-day recharge of plug-in hybrid electric vehicles: Energy impact of public charging infrastructure. Trans. Res. Part D Transp. Environ. 2012, 17, 405-412. [CrossRef]

10. Sioshansi, F.; Webb, J. Transitioning from conventional to electric vehicles: The effect of cost and environmental drivers on peak oil demand. Econ. Anal. Policy 2019, 61, 7-15. [CrossRef]

11. Wang, S.; Wang, J.; Li, J.; Wang, J.; Liang, L. Policy implications for promoting the adoption of electric vehicles: Do consumer's knowledge, perceived risk and financial incentive policy matter? Trans. Res. Part A Policy Pract. 2018, 117, 58-69. [CrossRef]

12. Myklebust, B. EVs in bus lanes-Controversial incentive. In Proceedings of the World Electric Vehicle Symposium and Exhibition, Barcelona, Spain, 17-20 November 2013.

13. Nie, Y.M.; Ghamami, M.; Zockaie, A.; Xiao, F. Optimization of incentive polices for plug-in electric vehicles. Trans. Res. Part B Methodol. 2016, 84, 103-123. [CrossRef]

14. Sykes, M.; Axsen, J. No free ride to zero-emissions: Simulating a region's need to implement its own zero-emissions vehicle (ZEV) mandate to achieve 2050 GHG targets. Energy Policy 2017, 110, 447-460. [CrossRef]

15. Siskos, P.; Moysoglou, Y. Assessing the impacts of setting $\mathrm{CO}_{2}$ emission targets on truck manufacturers: A model implementation and application for the EU. Trans. Res. Part A Policy Pract. 2019, 125, 123-138. [CrossRef]

16. Speidel, S.; Bräunl, T. Driving and charging patterns of electric vehicles for energy usage. Renew. Sustain. Energy Rev. 2014, 40, 97-110. [CrossRef] 
17. Morrissey, P.; Weldon, P.; Mahony, M.O. Future standard and fast charging infrastructure planning: An analysis of electric vehicle charging behaviour. Energy Policy 2016, 89, 257-270. [CrossRef]

18. Kihm, A.; Trommer, S. The new car market for electric vehicles and the potential for fuel substitution. Energy Policy 2014, 73, 147-157. [CrossRef]

19. Neaimeh, M.; Salisbury, S.D.; Hill, G.A.; Blythe, P.T.; Scoffield, D.R.; Francfort, J.E. Analysing the usage and evidencing the importance of fast chargers for the adoption of battery electric vehicles. Energy Policy 2017, 108, 474-486. [CrossRef]

20. Lin, Z.; Greene, D.L. Promoting the market for plug-in hybrid and battery electric vehicles: Role of recharge availability. Trans. Res. Rec. 2011, 2252, 49-56. [CrossRef]

21. Greene, D.L.; Kontou, E.; Borlaug, B.; Brooker, A.; Muratori, M. Public charging infrastructure for plug-in electric vehicles: What is it worth? Trans. Res. Part D Trans. Environ. 2020, 78, 102182. [CrossRef]

22. Kontou, E.; Liu, C.; Xie, F.; Wu, X.; Lin, Z. Understanding the linkage between electric vehicle charging network coverage and charging opportunity using GPS travel data. Trans. Res. Part C Emerg. Technol. 2019, 98, 1-13. [CrossRef]

23. Kley, F.; Lerch, C.; Dallinger, D. New business models for electric cars-A holistic approach. Energy Policy 2011, 39, 3392-3403. [CrossRef]

24. Patt, A.; Aplyn, D.; Weyrich, P.; Vliet, O. Availability of private charging infrastructure influences readiness to buy electric cars. Trans. Res. Part A Policy Pract. 2019, 125, 1-7. [CrossRef]

25. Siskos, P.; Zazias, G.; Petropoulos, A.; Evangelopoulou, S.; Capros, P. Implications of delaying transport decarbonisation in the EU: A systems analysis using the PRIMES model. Energy Policy 2018, 121, 48-60. [CrossRef]

26. Schroeder, A.; Traber, T. The economics of fast charging infrastructure for electric vehicles. Energy Policy 2012, 43, 136-144. [CrossRef]

27. Gnann, T.; Plötz, P.; Wietschel, M. How to address the chicken-egg-problem of electric vehicles? Introducing an interaction market diffusion model for EVs and charging infrastructure. In Proceedings of the ECEEE Summer Study, Toulon, France, 1-6 June 2015; pp. 873-884.

28. Baresch, M.; Moser, S. Allocation of e-car charging: Assessing the utilization of charging infrastructures by location. Trans. Res. Part A Policy Pract. 2019, 124, 388-395. [CrossRef]

29. Madina, C.; Zamora, I.; Zabala, E. Methodology for assessing electric vehicle charging infrastructure business models. Energy Policy 2016, 89, 284-293. [CrossRef]

30. Zhang, L.; Zhao, Z.; Xin, H.; Chai, J.; Wang, G. Charge pricing model for electric vehicle charging infrastructure public-private partnership projects in China: A system dynamics analysis. J. Clean. Prod. 2018, 199, 321-333. [CrossRef]

31. Zhang, L.; Yang, M.; Zhao, Z. Game analysis of charging service fee based on benefit of multi-party participants: A case study analysis in China. Sustain. Cities Soc. 2019, 48. [CrossRef]

32. Osterwalder, A.; Pigneur, Y. Business Model Generation: A Handbook for Visionaries, Game Changers, and Challengers; John Wiley \& Sons: Hoboken, NJ, USA, 2010.

33. Adler, M.; Bagemihl, J.; Bernard, G.; Biser, T.; Caleno, F.; Sanchez, J.M.C.; Densley, D.; Exposito, E.D.; Flader, L.; Martin, J.G.; et al. Eurelectric. Deploying publicly accessible charging infrastructure for electric vehicles: How to organise the market? Eurelectric Concept Pap. 2013. Dépôt légal: D/2013/12.105/35. Available online: https://www.eurelectric.org/media/1816/0702_emobility_ market_model_final_ac-2013-030-0501-01-e.pdf (accessed on 21 February 2021).

34. Papathanasiou, S.; Schina, O. Suggestions for the function of electro-mobility market in Greece. Rep. Regul. Auth. Energy 2019. (In Greek)

35. Energy Saving Trust. Procuring electric vehicle charging infrastructure as a local authority. Rep. Energy Sav. Trust. 2019.

36. International Energy Agency. Germany Charging Infrastructure. 2019. Available online: http://www.ieahev.org/by-country/ germany-charging-infrastructure/ (accessed on 20 April 2021).

37. Chen, D.; Jing, Z.; Tan, H. Optimal Bidding/Offering Strategy for EV Aggregators under a Novel Business Model. Energies 2019, 12, 1384. [CrossRef]

38. Guo, Y.; Liu, W.; Wen, F.; Salam, A.; Mao, J.; Li, L. Bidding Strategy for Aggregators of Electric Vehicles in Day-Ahead Electricity Markets. Energies 2017, 10, 144. [CrossRef]

39. Schiavo, L.; Bonafede, D.; Celaschi, S.; Colzi, F. Regulatory Issues in the Development of Electro-Mobility Services: Lessons Learned from the Italian Experience. In Proceedings of the 1st e-Mobility Power System Integration Symposium, Berlin, Germany, 23 October 2017.

40. Caleno, F.; Coppola, G. DSO business model for speeding up EVs mass market. In Proceedings of the 22nd International Conference on Electricity Distribution, Stockholm, Sweden, 10-13 June 2013.

41. Eurelectric. Charging Infrastructure for electric vehicles. Eurelectric Position Pap. 2016.

42. Lorentzen, E.; Haugneland, P.; Bu, C.; Hauge, E. Charging infrastructure experiences in Norway-The worlds most advanced EV market. In Proceedings of the EVS30 International Battery, Hybrid and Fuel Cell Electric Vehicle Symposium, Stuttgart, Germany, 9-11 October 2017.

43. Burger, S.P.; Luke, M. Business models for distributed energy resources: A review and empirical analysis. Energy Policy 2017, 109, 230-248. [CrossRef]

44. Capros, P.; Zazias, G.; Evangelopoulou, S.; Kannavou, M.; Fotiou, T.; Siskos, P.; Sakellaris, K. Energy-system modelling of the EU strategy towards climate-neutrality. Energy Policy 2019, 134, 110960. [CrossRef] 
45. Siskos, P.; Capros, P.; de Vita, A. $\mathrm{CO}_{2}$ and energy efficiency car standards in the EU in the context of a decarbonisation strategy: A model-based policy assessment. Energy Policy 2015, 84, 22-34. [CrossRef]

46. Hellenic Republic Ministry of the Environment and Energy. National Energy and Climate Plan. December 2019. Available online: https:/ / ec.europa.eu/energy/sites/ener/files/el_final_necp_main_en.pdf (accessed on 20 April 2021).

47. Nicholas, M.; Hall, D.; Lutsey, N. Quantifying the electric vehicle charging infrastructure gap across U.S. markets. ICCT White Pap. 2019.

48. Vagropoulos, S.; Kleidaras, A.; Bakirtzis, A. Financial Viability of Investments on Electric Vehicle Charging Stations in Workplaces with Parking Lots under Flat Rate Retail Tariff Schemes. In Proceedings of the Universities Power Engineering Conference, Cluj-Napoca, Romania, 2-5 September 2014.

49. Kang, N.; Feinberg, F.M.; Papalambros, P.Y. Integrated decision making in electric vehicle and charging station location network design. J. Mech. Des. 2015, 137, 061402. [CrossRef] 